\title{
When The Walls Listened
}

\author{
Susan Hiscoe Wisser
}

\author{
Copyright $\odot$ 1978, The American Journal of Nursing Company \\ Reprinted from American Journal of Nursing, June, Vol. 78 No. 6
}

$\mathbf{I}^{\mathrm{T}}$ T was my seventh consecutive night on duty, and it seemed by now that I could give the 11:00 p.m. report as well as the nurse who was going off. It was usually a busy intensive care unit, but for some time the patients had been fairly stable and the census low. So my interest was piqued when she said we had a new patient.

Mark, 25 years old, had been thrown from his motorcycle earlier that evening. Respiratory arrest followed. He had a tracheostomy, a respirator, multiple fractures, possible internal injuries and brain damage, and a urinary output that was alarmingly low. So far, the evening nurse said, his pupils were normal, and although unconscious and dependent on the respirator, he did respond slightly to deep pain.

"I'm sorry about all the dirt you'll find," she said. "It's imbedded an inch deep, and I just did not have time for that He's a handful.",

Her parting words echoed in my thoughts as I entered Mark's room. The bright overhead examining light left no shadow to soften the destruction that he had sustained. I smiled grimly as I saw the dirt and remembered the nurse's apology. I was not sure I'd be able to do much better myself.

I introduced myself to the unconscious man and took his hand. Palpating his pulse and beginning to check the maze of tubes that hissed, dripped, and drained, I said: "Mark, it looks like you got into a pretty nasty motorcycle accident. You have quite a few tubes here."

More to keep myself company than anything else, I continued to ramble on as I worked: "Mark, you are in the hospital and it's midnight. The new day will be Sunday. I bet your plans for today didn't include this." Using his name frequently helped transform the pallid figure into a human being.

Reducing the glaring lights to a soft glow. I explained the care that would follow. The minutes slipped past, regimented by endless needs and observations. At some point I washed away the outer layers of gravel and dirt gently; it would take more than one bath to remove the rest.

My 7:00 a.m. vital signs sheet showed that Mark had held his own for the night. although blood was appearing in the still-scant urine. "Good-bye Mark," I said, "I'm going home now. Another nurse will be with you during the day. " I did not look back as I left the unit. I was sure he would die.
Two days later it was a surprise to find him still there. His kidneys were functioning better, and now he triggered the respirator almost continuously. Perhaps there was a chance after all.

Mark became my special patient. Caring for him grew into more than an exercise in skilled nursing; the seed of hope took cautious root and grew.

Periodically, the odds seemed insurmountable. I was discouraged by his lack of response. The progress notes mentioned the possibility of brain damage, and I wondered if any mind existed in the shattered body we were trying so hard to salvage. Still I spoke to him as the person I wanted him to be: "Mark, the tube in your throat makes it impossible to talk. But it will not be there permanently."

One night the orderly was helping me change his bed. "Mark, we are going to turn you on your right side now." I said. "l'm sorry my hands are so cold."

My assistant looked at me curiously. "Who are you talking to, the walls?"

The question touched my helplessness and futility. I could only reply sadly, "I don't know. Perhaps you are right only the walls." Time inched by the rest of the night. Mark seemed more like an inert lump than anything else. In an unreasonable way I felt angry, as though he had let me down.

The next night I arrived full of resolutions to do better with Mark. However, the report from the evening nurse made my attitude an issue of very low priority. During the day he had haemorrhaged internally and had been taken to surgery. Postoperatively he developed complete renal failure. A shunt had been inserted. and dialysis started.

There was so much equipment in Mark's room that it looked like a storage closet. Getting to the bed was a trick. The dialysis technician smiled at me from his perch near the kidney machine. Mark was lost under the web of dressings, tubes, and coils. My heart was full and threatening to spill over. My best ICU intuition told me that the end could not be far away. The body could endure only so much.

That night I spoke softly as I worked, explaining and reassuring as a mother sings a lullaby to soothe a child. I was aware of my touch; it must be gentle. None of this attention took any extra time. Caring is a state of mind, not additional work. 
Mark lived through the night and was even becoming a bit restless as I prepared to leave. Cerebral hypoxia. or consciousness?

The following evening the resltessness had increased. He was fighting the respirator. and restraints had been applied to guarantee the placement of the various tubes. Morphine was being administered in large doses on a prn basis. The possibility of using curare had been raised by the doctors.

At his bedside, 1 could sense a change. His hand seemed to close on mine as I held it during my usual greeting. He was drenched with perspiration. Did the muscles relax just a bit as I wiped his face with a cool cloth? Slowly, fervently, I went through the oft-repeated explanations . . . the accident, the pain, the lack of voice, the treatment.

It was natural to continue: “Mark, you've been very restless. Your hands are restrained to keep the tubes still and safe. It's not comfortable for you. I will loosen them if you can lie quietly." Wondering if I were crazy, I untied the bands that fastened his arms to the bed. Mark lay still. He appeared to relax and the strain left his face. Every muscle in my body tensed to stop any movement, but he remained calm. The I.V. dripped. the respirator hissed. but Mark did not move. Hope renewed itself a thousandfold pushing back the walls of the stifling room. It is not a miracle, I kept telling myself, but underneath I bet that it was.

I cared for Mark only one night before going away to school. He had not regained consciousness, and a few people were sceptical about my optimistic reports. But I had spent all those nights striving to communicate with my patient and felt reasonably certain that $I$ had succeeded.

Over Thanksgiving break. I returned home and went to the hospital to visit old friends. We were talking at the central nurses" station when a man in a wheelchair came through the doors. He was obviously accustomed to visiting, and everyone greeted him warmly. I asked who he was.

"Oh, Mark is one of our miracles," she said. "I don't know if you were here when he came. A bad motorcycle accident.'

I had to fight back tears. It had been months ago. The man before me was laughing and healthy. He had a moustache. No tubes pierced his skin. How many times had I prayed to hear his voice reply to mine and now at last I would.

"Mark," I began hesitantly. "you probably don't remember me, but I took care of you right after the accident."

The young man's face grew serious, and his eyes held mine. His expression forbade any further comment. The seconds passed. whirling backward into the depths of pain and darkness. His hand trembled as he stretched it to me.

In a low voice he said: "Yes, God, I remember your voice. It was the only way I knew I was alive and not dead. You were the first one who told me what the hell had happened. I was scared to death, but then l'd hear your voice, and I knew I would be all right."

Suddenly I was back in the crowded room with him, faltering but daring to hope, talking to the walls night after night. How wonderful it was to know that the walls were listening

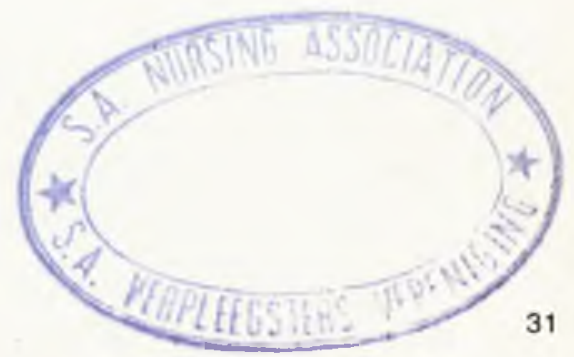

